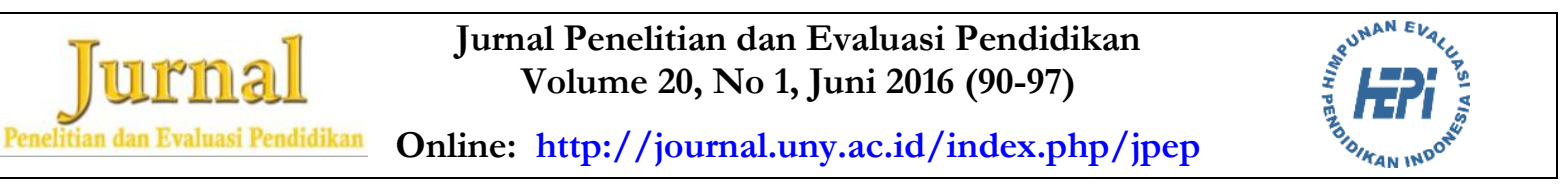

\title{
EKSPLORASI PERMASALAHAN \\ DALAM IMPLEMENTASI COMMUNITY-BASED EDUCATION DI FAKULTAS KEDOKTERAN
}

\author{
${ }^{1)}$ Vivi Meidianawaty, ${ }^{2)}$ Widyandana, ${ }^{3)}$ Tri Nur Kristina \\ ${ }^{1)}$ Fakultas Kedokteran Universitas Swadaya Gunung Jati, Cirebon \\ ${ }^{2)}$ Fakultas Kedokteran Universitas Gadjah Mada, Yogyakarta \\ ${ }^{3)}$ Fakultas Kedokteran Universitas Diponegoro, Semarang \\ ${ }^{1)}$ vivi.meidianawaty@gmail.com
}

\begin{abstract}
Abstrak
Penelitian ini bertujuan untuk mengeksplorasi permasalahan-permasalahan yang dapat ditemukan saat implementasi Community-based Education (CBE) di fakultas kedokteran. Pendekatan kualitatif eksplorasi dilakukan untuk mengidentifikasi permasalahan yang sering ditemui dalam implementasi program CBE. Pengumpulan data dilakukan di fakultas kedokteran negeri dan swasta dengan evaluasi dokumen, wawancara semistruktur, dan observasi. Kesimpulan dari penelitian ini adalah program CBE yang tidak menetapkan tujuan pembelajaran bersifat generik, kurang melibatkan peran aktif masyarakat dalam kegiatan pembelajaran mahasiswa, kebutuhan masyarakat yang jarang teridentifikasi, dan tidak adanya program yang berkelanjutan dapat menyebabkan kejenuhan masyarakat atau kegagalan program CBE mencapai tujuannya.
\end{abstract}

Kata kunci: community-based education, implementasi, masalah, metode berkelanjutann

\section{EXPLORATION OF PROBLEMS IN COMMUNITY-BASED EDUCATION IN THE FACULTY OF MEDICINE}

\author{
${ }^{1)}$ Vivi Meidianawaty, ${ }^{2)}$ Widyandana, ${ }^{3)}$ Tri Nur Kristina \\ ${ }^{1)}$ Fakultas Kedokteran Universitas Swadaya Gunung Jati, Cirebon \\ ${ }^{2)}$ Fakultas Kedokteran Universitas Gadjah Mada, Yogyakarta \\ ${ }^{3}$ Fakultas Kedokteran Universitas Diponegoro, Semarang \\ ${ }^{1)}$ vivi.meidianawaty@gmail.com
}

\begin{abstract}
There were sereval problems in the implementation of Community-based Education CBE that need to be further explored. Exploratory qualitative approach was carried out to identify problems that were often encountered. Data collection was conducted in Public Medical School and Private Medical School by using document evaluation, semi-structured interviews, and observation. The conclusion of this study is CBE program that does not set the generic learning objectives, less involvement of the community active participation, the needs of community who are rarely identified, and the absence of a sustainable program can lead to saturation of the CBE program or failure to achieve its objectives.
\end{abstract}

Keywords: community-based education, implementation, problems, sustainable methods 


\section{Pendahuluan}

Community-Based Education (CBE) adalah suatu bentuk kegiatan belajar dimana mahasiswa mempelajari kompetensi seorang dokter di masyarakat sekaligus membantu mahasiswa membangun hubungan dengan masyarakatnya (WHO Regional Office for the Eastern Mediteranean, 2014). Konsep CBE ini perlu diimplementasikan sebagai upaya meningkatkan kualitas layanan kesehatan dokter di masyarakat.

Implementasi CBE pada beberapa negara bervariasi tergantung dari kebutuhan kesehatan masyarakatnya, sistem pelayanan kesehatan yang digunakan, dan tujuan belajar program CBE (Magzoub \& Schmidt, 2000). Implementasi CBE di Eropa dan Amerika umumnya dilakukan dengan mengirimkan mahasiswa untuk magang di tempat praktik dokter keluarga atau spesialis, dan atau melakukan pelayanan sosial (Cauley et al., 2001). Chastonay et al. (2012) dalam penelitiannya memberikan contoh sebuah program pengenalan pada pelayanan pasien rawat jalan. Tujuannya adalah untuk memperkenalkan mahasiswa pada berbagai aspek pelayanan kesehatan primer. Lebih khusus mahasiswa berkenalan dengan tugastugas profesional dari dokter umum dan belajar untuk mengintegrasikan pengelolaan pasien yang berkelanjutan dalam praktik sehari-hari. Implementasi CBE di negaranegara berkembang seperti di Afrika dan Asia, dilaksanakan dengan mengirimkan mahasiswa ke daerah-daerah pedesaan, sarana pelayanan kesehatan masyarakat primer atau ke komunitas tertentu. Kristina, et al., (2006) melakukan penelitian terhadap kegiatan yang dilakukan mahasiswa meliputi mengidentifikasi masalah, mencari solusi intervensi bersama masyarakat, melaksanakan sampai mengevaluasi hasil intervensi.

Meskipun dalam penerapannya terdapat berbagai variasi, namun masalah yang ditemukan dalam implementasi CBE hampir sama. Masalah utama program CBE meliputi perancangan program, perencanaan program CBE, lokasi/komunitas, dan implementasi program. Permasalahan yang berhubungan dengan kurikulum dan sum- ber daya sampai pengorganisasian permasalahan dapat menjadi kelemahan dari implementasi program CBE (Hamad, 1991).

Mengingat belum banyak penelitian mengenai implementasi CBE di Indonesia, maka belum banyak diketahui tentang permasalahan yang ditemukan saat CBE diimplementasikan di fakultas kedokteran. Oleh karena itu diperlukan penelitian yang dapat memberikan informasi mengenai bagaimana implementasi CBE dan permasalahan yang ditemukan pada saat impelementasinya.

\section{Metode Penelitian}

Penelitian ini menggunakan metodologi kualitatif eksplorasi untuk mengidentifikasi permasalahan yang dapat muncul saat implementasi program CBE. Penelitian dilakukan di satu fakultas kedokteran negeri (Institusi A) dan satu fakultas kedokteran swasta (Institusi B). Subjek pada penelitian ini adalah staf pengajar pada masing-masing institusi yang merupakan penanggung jawab dan pelaksanan program CBE. Proses pemilihan informan dipilih yaitu penanggung jawab program dan staf yang telibat dalam program CBE (pembimbing CBE di lapangan) minimal 3 tahun.

Pengumpulan data dilakukan dengan cara mengevaluasi dokumen, wawancara semi-terstruktur dan observasi. Pada evaluasi dokumen digunakan panduan yang peneliti kembangkan sendiri berdasarkan Buku Desain \& Implementasi Pembelajaran Berbasis Masyarakat di Fakultas Kedokteran yang ditulis oleh Kristina (2011). Dokumen yang dianalisis adalah buku panduan pelaksanaan $\mathrm{CBE}$, buku pedoman $\mathrm{KKN}$, dan laporan kegiatan. Aspek-aspek yang dinilai pada buku panduan pelaksanaan dan buku pedoman KKN meliputi tujuan pembelajaran, dasar teori, kegiatan belajar, penilaian untuk mahasiswa, dan tata tertib kegiatan. Pada laporan kegiatan dinilai kesesuaian kegiatan yang dilaksanakan dengan perencanaan yang ada di buku panduan pelaksanaan. Wawancara semi-terstruktur dilakukan dengan menggunakan daftar pertanyaan yang sudah disiapkan sebagai panduan yang 
telah disusun dengan merujuk pada artikel Twelve Tips for Community-based Bedical Education oleh Howe dan Buku Desain \& Implementasi Pembelajaran Berbasis Masyarakat di Fakultas Kedokteran oleh Kristina. Wawancara dilakukan sendiri oleh peneliti. Wawancara dilakukan sebanyak 1 kali selama 30 menit -1 jam pada setiap informan. Pada saat wawancara, dilakukan pencatatan oleh peneliti dan perekaman dengan menggunakan audio recorder. Observasi dilakukan oleh peneliti dengan mengamati kegiatan program di lokasi atau tempat pembelajaran menggunakan panduan yang peneliti kembangkan berdasarkan Buku Desain \& Implementasi Pembelajaran Berbasis Masyarakat di Fakultas Kedokteran yang ditulis oleh Kristina (2011). Pada saat observasi dilakukan pencatatan dan direkam dengan menggunakan kamera. Aspek-aspek yang diamati meliputi lokasi atau tempat belajar, kegiatan belajar, dosen pembimbing, mahasiswa, dan masyarakat. Kegiatan di Institusi A yang diobservasi adalah kegiatan survei kesehatan dan kegiatan edukasi pada siswa sekolah dasar. Observasi dilakukan sebanyak 1 kali. Observasi kegiatan di Institusi B dilakukan pada blok 3.1, 5.3, 6.1, 6.3. Observasi dilaksanakan selama program $\mathrm{CBE}$ berjalan yaitu 1 minggu.

Peneliti melakukan analisis data dengan mereduksi data yang diperoleh menjadi informasi yang memiliki makna namun lebih ringkas. Pada tahap pertama dilakukan dengan membaca keseluruhan data untuk membangun pemahaman umum dari informasi yang diperoleh. Selanjutnya, pada langkah dilakukan dengan menganalisis lebih detail dengan meng-coding data. Langkah ini melibatkan beberapa tahap yaitu mengambil data tulisan atau gambar yang telah dikumpulkan, mensegmentasi kalimat kemudian dikelompokkan ke dalam kategori. Setelah itu mencari hubungan antarkategori-kategori. Tahap yang terakhir pada analisis data adalah menetapkan tema untuk menjadi sebuah deksripsi umum.

Upaya keabsahaan data pada penelitian ini dilakukan dengan merujuk pada strategi-strategi keabsahan data kualitatif yang disarankan oleh Creswell (2003) yaitu sebagai berikut.

Pertama adalah Intercoder agreement. Persetujuan ini didasarkan pada 2 atau lebih pemeriksa kata kunci yang telah sepakat mengenai kata kunci-kata kunci yang ada pada data. Pada penelitian ini dilakukan pencarian kata kunci oleh peneliti dan 1 orang dosen dengan latar belakang pendidikan kedokteran. Pada saat terjadi ketidaksepakatan maka akan dibandingkan dengan teori atau penelitian sebelumnya.

Kedua adalah Triangulate. Data dikumpulkan dari berapa sumber yaitu dokumen, wawancara semi-terstruktur, dan observasi. Ketiga adalah Member checking. Proses ini dilakukan dengan membawa kembali laporan deksripsi atau tema kepada informan untuk mengecek apakah tema atau deskripsi yang telah dibuat oleh peneliti sudah akurat. Bagi informan yang berasal dari Institusi A hasil analisis dikirimkan melalui email.

Penelitian ini telah mendapatkan persetujuan dari Komisi Etik Penelitian Fakultas Kedokteran Universitas Gadjah Mada.

\section{Hasil Penelitian dan Pembahasan}

Gambaran secara umum dari implementasi CBE di ke 2 institusi adalah sebagai berikut: Sejak 2013, Institusi A mulai melaksanakan program CBE bersamaan dengan program Kuliah Kerja Nyata (KKN) yang diselenggarakan oleh pihak universitas. Program ini dilaksanakan di semester akhir atau semester 7. Mahasiswa ditempatkan di desa-desa yang telah ditentukan oleh universitas. Pada 1 desa ditempatkan 1-2 orang mahasiswa dari fakultas kedokteran. Setiap mahasiswa mendapat tugas untuk melakukan survei kesehatan, kemudian menentukan prioritas masalah dan menentukan intervensinya bersama dengan masyarakat. Setiap mahasiswa dibekali buku pedoman KKN. Untuk pendampingan selama mahasiswa menjalani program tersebut disediakan 2 orang dosen pembimbing lapangan untuk 1 kecamatan, dan diakhir program mahasiswa membuat laporan untuk setiap kegiatan yang telah dilaksanakan dilengkapi dengan $\log$ book. 
Program CBE diimplementasikan sejak tahun 2010 di Institusi B. Untuk mempersiapkan program ini, fakultas terlebih dahulu mengadakan MOU dengan Dinas Kesehatan setempat untuk penyediaan lahan pendidikan dan instruktur untuk program $\mathrm{CBE}$. Pemetaan program $\mathrm{CBE}$ dalam kurikulum tersebar pada setiap tingkatan disesuaikan dengan level kompetensi yang ingin dicapai. Kegiatan CBE sebagian besar dilakukan oleh bagian keterampilan klinik dengan tujuan kegiatan yang terintegrasi dengan blok yang berjalan. Tempat belajar dilakukan di Puskesmas atau langsung di masyarakat. Jangka waktu kegiatan CBE ini sekitar 1 minggu. Selain kegiatan CBE yang dilakukan oleh bagian keterampilan klinik ada juga yang dilakukan pada Blok implementation of family medicine and community bealth, dimana mahasiswa menghabiskan waktu selama 4 minggu di lapangan, baik di puskesmas atau di masyarakat. Tujuan dari blok ini mahasiswa mampu mengaplikasikan pengetahuan yang telah didapat pada tahap sebelumnya terutama yang terkait dengan kedokteran keluarga dan kesehatan masyarakat. Selama kegiatan CBE mahasiswa didampingi oleh dosen pembimbing yang berasal dari puskesmas.

Hasil dari penelitian menunjukkan bahwa permasalahan-permasalahan yang muncul saat implementasi program $\mathrm{CBE}$ dapat berasal dari perancangan program yaitu dengan penentuan tujuan pembelajaran yang belum bersifat generik, tujuan belajar kurang dipahami oleh pembimbing dan mahasiswa, lamanya program, tidak adanya program yang berkelanjutan, kurang dilibatkannya peran aktif dari masyarakat saat kegiatan belajar mahasiswa, komitmen dari pembimbing di lapangan dan munculnya kejenuhan masyarakat terhadap program CBE.

Tema-tema yang muncul pada penelitian ini adalah sebagai berikut.

Kurang Dipahaminya Tujuan Program CBE

Pada Institusi B, tujuan pembelajaran sudah tercantum pada buku pedoman pelaksanaannya. Meskipun demikian tujuan program $\mathrm{CBE}$ ini dirasakan masih belum jelas dipahami oleh para pembimbing dan mahasiswa terutama di awal penerapan program CBE.

"......modul yang disiapkan kurang jelas, tujuan pembelajaran kurang jelas sebingga membingungkan untuk mahasiswa." (Responden 2)

"Terutama pada saat di awal-awal ya, yang pada saat kita, saya di puskesmas sini juga masib belajar, mahasiswa juga yang memang baru turun ke puskesmas. Kadang mereka bingung mau cari apa di puskesmas." (Responden 3)

"....biasanya di hari pertama mahasiswa kurang persiapan. Mahasiswa masib belum paham apa yang akan mereka pelajari di puskesmas.." (Responden 4)

Hasil evaluasi dokumen di kedua institusi menunjukkan bahwa harapan agar mahasiswa melibatkan peran aktif dari masyarakat dalam kegiatannya masih belum optimal. Pada buku pedoman kegiatan di institusi A belum tercantum tujuan belajar untuk mahasiswa agar melibatkan masyarakat dalam kegiatannya. Untuk Institusi B tujuan belajar yang mengharapkan mahasiswa untuk melibatkan partisipasi masyarakat dalam kegiatannya baru ada di blok terakhir

Implementasi Program CBE dalam Kurikulum

Program CBE di Institusi A hanya dilaksanakan satu kali yaitu di semester akhir atau semester 7 bersamaan dengan program KKN.

" Untuk pogram CBE itu kami punya program sebelum dia dinyatakan lulus jadi sarjana kedokteran yaitu pada semester 7 ". (Responden 1)

Program CBE dalam kurikulum Institusi B tersebar pada setiap tingkatan disesuaikan dengan level kompetensi yang ingin dicapai. Kegiatan $\mathrm{CBE}$ sebagian besar dilakukan oleh bagian keterampilan klinik dengan tujuan kegiatan yang terintegrasi dengan blok yang berjalan. Di semester $7 \mathrm{ma-}$ 
hasiswa pada Institusi B akan melaksanakan kegiatan CBE secara lebih terintegrasi. Meskipun demikian masih belum terlihat adanya program yang berkelanjutan. Kegiatan yang dilaksanakan banyak menguntungkan dari segi mahasiswa karena mahasiswa dapat belajar keterampilan klinis secara langsung pada pasien.

Kegiatan belajar yang tidak sesuai tujuan belajar juga disadari oleh pembimbing sebagai kelemahan implementasi program CBE pada institusi B. Contohnya untuk mahasiswa semester 6 diharapkan mahasiswa mampu mengidentifikasi permasalahan kesehatan masyarakat melalui survei kesehatan, tetapi pada praktiknya mahasiswa baru mengidentifikasi di tingkat perorangan, seperti komentar responden di bawah ini.

"Praktik pembelajaran yang telah dilakukan selama ini masib berfokus pada usaba kesehatan perorangan dalam bentuk wawancara pasien yang datang ke puskesmas. Praktik tersebut tidak mengambil sebagian dari masyarakat untuk di wawancara. Sebingga permasalahan yang dikajïpun adalah pemasalaban perorangan dan bukan masyarakat." (Responden 4)

Pembimbing juga merasakan bahwa waktu yang dihabiskan mahasiswa semester 1 di puskesmas selama 1 hari untuk melihat tugas dan peran dokter puskesmas masih sangat kurang.

"Community based-nya kurang optimal. Waktunya hanya 1 hari, akifitasnya hanya observasi kegiatan di dalam gedung. Alokasi waktu tersebut kurang memadai untuk memotret gambaran umum kegiatan dalam gedung. Sedangkan kegiatan kesehatan masyarakat yang fokusnya luar gedung (kunjungan rumah, posyandu, posbindu, musyawarb warga, dsb.) tidak terekam". (Responden 4)

Dari hasil pengamatan mengenai aktivitas belajar mahasiswa pada kedua institusi didapatkan variasi kegiatan belajar di beberapa tempat seperti puskesmas, posyandu, posyandu lansia, sekolah dasar, dan keluarga. Kegiatan-kegiatan tersebut memberikan kesempatan kepada mahasiswa untuk belajar langsung di masyarakat. Meskipun de- mikian, harapan agar mahasiswa melibatkan masyarakat secara aktif dalam kegiatannya belum terlihat. Masyarakat baru sebatas sebagai pasien dalam pembelajaran keterampilan klinik, sebagai responden dalam kegiatan survei kesehatan atau sebagai peserta dalam kegiatan penyuluhan kesehatan. Contohnya adalah saat mahasiswa melakukan kegiatan edukasi di sekolah dasar, mahasiswa memberitahukan pihak sekolah mengenai kegiatan tersebut. Pemilihan materi edukasi yang akan diberikan ditentukan sendiri oleh mahasiswa belum berdasarkan kebutuhan yang dirasakan oleh masyarakat.

Peran dan Tugas Pembimbing Program CBE

Pelaksanaan program CBE mengambil tempat di luar institusi seperti di puskesmas atau posyandu, ini berarti institusi membagi tugas dan tanggung jawab pendidikan bersama institusi lain. Pembimbing harus membagi peran dan tugasnya antara sebagai pelayan kesehatan dan pendidikan. Keterbatasan waktu untuk melaksanakan tugas pendidikan disadari oleh para pembimbing di puskesmas.

"Karena sebagian besar yang dijadikan pembimbing adalah kepala puskesmas dan sering diundang rapat sehingga waktu untuk membimbing mahasiswa menjadi terbatas." (Responden 2)

Kegiatan belajar yang mengharuskan mahasiswa untuk ke luar gedung puskesmas juga menjadi kendala bagi para pembimbing untuk dapat mendampingi mahasiswa saat kegiatannya. Hal ini membuat pembimbing harus mendelegasikan tugasnya kepada tenaga medis lain yang belum dilatih sebagai pembimbing mahasiswa untuk program CBE.

"Nanti kalau di lapangan, misalnya imunisasi saya akan kasib tau ke petugas imunisasi. Kalau ada kegiatan di bagian gizi nanti akan saya kasih tau ke petugas gizi. Kemudian pada saat nanti di dalam gedung ada beberapa pos yang harus dimasuki ya saya koordinasi dengan petugas atau programmer yang akan membimbing mahasiswa”. (Responden 3) 
"Karena keterbatasan saya sebagai pembimbing harus menilai, tetep inti-inti dari penilaian itu saya delegasikan ke tiap-tiap pos yang meihat langsung kegiatan dari adik-adik mahasiswa. Jadi nanti mereka akan memberikan masukkan ke saya”. (Responden 3)

Kejenuhan terhadap program CBE

Kejenuhan masyarakat terhadap program CBE yang beberapa kali diterapkan pada suatu komunitas akan menjadi hambatan terhadap kesuksesan program CBE.

"Pada awalnya masyarakat masyarakat akan merasa senang, welcome,namun setelah beberapa siklus begitu akan ada kejenuban." (Responden 1)

Institusi A mengiplementasi program CBE pada akhir semester 7 dengan mengikutkan mahasiswa pada program KKN yang diselenggarakan oleh universitas. Program CBE yang hanya ada di semester akhir sebagaimana yang diimplementasikan di Institusi A kurang sesuai dengan tujuan program CBE pada umumnya yaitu untuk meningkatkan derajat kesehatan masyarakat. Dengan program CBE yang hanya ada di akhir semester tentunya tidak ada suatu program yang berkelanjutan yang dapat menghubungkan program CBE yang satu dengan yang lainnya sehingga manfaat dari program CBE dapat dirasakan oleh masyarakat.

Tujuan program CBE di Institusi A sebenarnya sudah mencerminkan tujuan pembelajaran yang bersifat generik, namun tujuan ini tidak tercantum di buku pedoman KKN. Tujuan pembelajaran yang tidak tercantum dalam buku pedoman seperti yang ada di Institusi A dapat membuat mahasiswa tidak bisa memahami apa yang harus dicapai selama mengikuti program tersebut. Tujuan pembelajaran ini harus diketahui oleh pembimbing dan mahasiswa termasuk kegiatan yang harus dilakukan oleh mahasiswa agar tujuan pembelajaran tersebut dapat tercapai.

Kegiatan belajar yang dilaksanakan pun masih belum terlihat melibatkan peran aktif dari masyarakat atau berdasarkan kebutuhan dari masyarakat tersebut. Commu- nity-based education memiliki implikasi yang luas pada seluruh proses pendidikan dan keterlibatan masyarakat merupakan bagian tak terpisahkan dari proses perkembangan pendidikannya.

Hasil penelitian di Institusi A ditemukan bahwa masyarakat mengalami kejenuhan terhadap kegiatan mahasiswa saat melaksanakan program CBE. Hal ini juga dialami oleh Christian Medical College di Vellore India saat melaksanakan program CBE mereka. Kegagalan program CBE untuk melibatkan peran aktif masyarakat dalam kegiatan pembelajaran mahasiswa, kebutuhan masyarakat yang jarang teridentifikasi, dan tidak adanya program yang berkelanjutan dapat menyebabkan kejenuhan atau keengganan masyarakat terhadap program CBE.

Institusi B memetakan program CBE dalam kurikulumnya tersebar dari semester awal hingga semester akhir tahap sarjana kedokteran. Namun, hal tersebut baru menguntungkan dari aspek mahasiswa dan belum terlihat adanya program yang berkelanjutan berdasarkan permasalahan kesehatan masyarakat yang menguntungkan dari aspek masyarakatnya. Dalam pengembangan kurikulum program CBE disarankan untuk dapat diterapkan dengan menggunakan metode berkelanjutan dari semester awal sampai akhir sehingga aspek tingkat kesulitan dalam belajar dapat disesuaikan dengan level mahasiswa. Disamping itu, metode berkelanjutan dapat menghubungkan antara program $\mathrm{CBE}$ yang satu dengan yang lainnya dan maanfaat dari program CBE dapat dirasakan oleh masyarakat. Durasi mahasiswa mengikuti program CBE dirasakan oleh pembimbing masih belum cukup untuk mendapatkan gambaran yang utuh mengenai puskesmas. Memang belum ada kesepakatan mengenai berapa lama sebaiknya program CBE dilaksanakan, namun menurut Talaat \& Ladhani bahwa rata-rata beberapa fakultas menerapkan program $\mathrm{CBE}$ selama 1 bulan dalam setahun di tempat yang sama.

Program CBE adalah proses pembelajaran mahasiswa yang mengambil tempat di luar institusi. Kurangnya pengawasan da- 
pat terjadi selama masa pelaksanaannya dan akan membuat program CBE tidak berjalan sesuai dengan yang sudah direncanakan. Tujuan pembelajaran ini harus diketahui oleh pembimbing dan mahasiswa termasuk kegiatan yang harus dilakukan oleh mahasiswa agar tujuan pembelajaran tersebut dapat tercapai (6). Pada penelitian ini didapatkan bahwa meskipun tujuan pembelajaran sudah tercantum dalam buku pedoman di Institusi $\mathrm{B}$, namun tujuan pembelajaran tersebut dirasakan oleh pembimbing masih kurang jelas terutama pada masa-masa awal pelaksanaan program CBE walaupun persiapan untuk pembimbing sudah dilaksanakan sebelum program dimulai. Permasalahan seperti tersebut juga pernah ditemukan oleh oleh Kaye et al., (2011) saat melakukan eva-luasi program CBE di Uganda bahwa in-struktur masih belum memahami kurikulum, terutama mengenai kompetensi yang diharapkan termasuk bagaimana kurikulum diimplementasikan.

Dalam menyusun kegiatan belajar untuk program CBE Institusi B sudah melaksanakan dengan baik yaitu terjun langsung ke masyarakat baik di puskesmas, lingkungan RW maupun di tingkat keluarga. Apapun tujuan belajar yang telah ditetapkan oleh institusi, kegiatan belajar yang diselenggarakan harus dapat memberikan pengalaman belajar kepada mahasiswa. Namun demikian, saat melaksanakan kegiatan peran aktif dari masyarakat kurang dilibatkan. Disebutkan oleh Kristina bahwa kegiatan-kegiatan yang dilaksanakan harus berdasarkan kebutuhan masyarakat dan harus ada peran aktif dari masyarakat untuk ikut terlibat karena salah satu faktor penting yang menentukan keberlanjutan dari suatu program CBE adalah adanya peran aktif dari masyarakat, tanpa adanya keterlibatan masyarakat maka program CBE tidak akan memberikan manfaat.

Peneliti menyadari bahwa dalam penelitian ini masih banyak beberapa kekurangan diantaranya adalah: (1) penelitian baru dilakukan pada 2 institusi, sehingga tidak cukup menggambarkan implementasi program CBE pada fakultas kedokteran di Indonesia; (2) penelitian belum menggali data dari mahasiswa dan masyarakat sebagai bagian dari komponen program CBE; (3) penelitian belum mencakup outcome program $\mathrm{CBE}$ sehingga belum dapat mengevalusi program $\mathrm{CBE}$ secara keseluruhan. Untuk itu diperlukan penelitian lanjutan agar didapatkan gambaran secara utuh pelaksanaan program CBE pada fakultas kedokteran di Indonesia. Selain itu persepsi peneliti terhadap implementasi program CBE terbentuk dari pengalaman pribadi peneliti tentu membawa bias-bias tersendiri ke dalam penelitian ini. Akan tetapi, bias-bias ini membantu bagaimana peneliti memandang dan memahami data yang dikumpulkan.

\section{Simpulan}

Berdasarkan hasil penelitian dan pembahasan yang telah dilakukan, didapatkan beberapa permasalahan saat implementasi program CBE di kedua institusi yaitu dengan penentuan tujuan pembelajaran yang belum bersifat generik, tujuan belajar kurang dipahami oleh pembimbing dan mahasiswa, lamanya program, tidak adanya program yang berkelanjutan, kurang dilibatkannya peran aktif dari masyarakat saat kegiatan belajar mahasiswa, komitmen dari pembimbing di lapangan dan munculnya kejenuhan masyarakat terhadap program $\mathrm{CBE}$.

Beberapa hal yang dapat peneliti sarankan berdasarkan temuan pada penelitian ini yaitu menetapkan tujuan program $\mathrm{CBE}$ yang bersifat generik yang responsif terhadap kebutuhan masyarakat, menerapkan metode berkelanjutan pada program CBE, mensosialisasikan tujuan pembelajaran dan kegiatan mahasiswa, melakukan pelatihan untuk semua yang dapat dijadikan pembimbing, mempertimbangkan beberapa lokasi yang berbeda untuk mencegah kejenuhan dari masyarakat, dan melibatkan peran aktif masyarakat dalam kegiatan belajar.

\section{Daftar Pustaka}

Cauley, K., Canfield, A., Clasen, C., Dobbins, J., Hemphill, S., Jaballas, E., 
\& Walbroehl, G. (2001). Service Learning: Integrating Student Learning and Community Service. Education for Health (Abingdon, England), 14, 173-181.

Habbick, B. F., \& Leeder, S. R. (1996). Orienting medical education to community need: a review. Medical Education, 30(3), 163-71. Retrieved from

http://www.ncbi.nlm.nih.gov/pubme d/8949549

Hamad, B. (1991). Community-oriented medical education: what is it? Medical Educatin, 25(1), 16-22. Retrieved from http://www.ncbi.nlm.nih.gov/pubme d/1997823

Howe, A. (2002). Twelve tips for community-based medical education. Medical Teacher, 24(1), 100-2. http://doi.org/10.1080/00034980120 103423

Kaye, D. K., Muhwezi, W. W., Kasozi, A. N., Kijjambu, S., Mbalinda, S. N., Okullo, I., ... Mwanika, A. (2011). Lessons learnt from comprehensive evaluation of community-based education in Uganda: a proposal for an ideal model community-based education for health professional training institutions. BMC Medical Education, $\quad 11(1), \quad 7$. http://doi.org/10.1186/1472-692011-7

Kristina, T. N. (2011). Desain dan Implementasi Pembelajaran Berbasis Masyarakat di Fakultas Kedokteran. (T. N. Kristina, Ed.). Yogyakarta: Bagian Pendidikan Kedokteran FK UGM.
Kristina, T. N., Majoor, G., \& Van Der Vleuten, C. (2006). Does Community-Based Education come close to what it should be? A case study from the developing world: students' opinions. Education for Health (Abingdon, England), 19(2), 179-88. http://doi.org/10.1080/13576280600 783596

Magzoub, M. E., \& Schmidt, H. G. (2000). A taxonomy of community-based medical education. Academic Medicine: Journal of the Association of American Medical Colleges, 75(7), 699-707. Retrieved from http://www.ncbi.nlm.nih.gov/pubme d/10926020

Omotara, B. a, Yahya, S. J., Shehu, U., Bello, H. S., \& Bassi, a P. (2006). Communities' awareness, perception and participation in the CommunityBased Medical Education of the University of Maiduguri. Education for Health (Abingdon, England), 19(2), 14754.

http://doi.org/10.1080/13576280600 783661

Talaat, W., \& Ladhani, Z. (2014). Community Based Education in Health Professions: Global Perspectives. Regional Office for Eastern Mediterranean of World Health Organization.

WHO Regional Office for the Eastern Mediteranean. (2014). Community-based Education in Health Proffesions: Global Perspectives. (W. Talaal \& Z. Ladhani, Eds.). World Helath Organization.

WHO Study Group Report. (1987). Community based education of bealth personel. Geneva. 